\title{
ANTI-CANCER POTENTIAL OF POLYSACCHARIDE ISOLATED FROM METHANOLIC EXTRACT OF TINOSPORA CORDIFOLIASTEM BARK
}

\author{
ANTONY LUDAS², SABAPATHY INDU², SEKAR HINDUJA², ANTHONISAMY KUMARI NIRMALA2, MANIKKAM \\ RAJALAKSHMI ${ }^{1,2^{*}}$
}

1PG and Research Department of Zoology, Holy Cross College (Automonous), Tiruchirappalli, India, ${ }^{2} \mathrm{PG}$ and Research Department of Biotechnology and Bioinformatics, Holy Cross College, (Automonous), Tiruchirappalli, India

Email: mdraji@gmail.com

Received: 06 May 2017 Revised and Accepted: 29 Mar 2019

\section{ABSTRACT}

Objective: The exploration of the anticancer potential of polysaccharide isolated from the methanolic extract of Tinospora cordifolia (T. cordifolia) stem bark against breast cancer in DMBA-induced female albino Wistar rat models were examined by various hematological parameters.

Methods: Analysis of Red blood cell (RBC), White blood cell (WBC) and platelet level, Tumor markers Carcino Embryonic Antigen (CEA) and Cancer Antigen 15.3 (CA 15.3) in the serum, was done in the normal, cancer and compound treated rats using specific kits. Histological studies were performed to examine the changes in the tissue morphology and cell patterns in breast tissue.

Results: The decreased levels of RBC, WBC and platelets in 7,12-Dimethylbenz [a] anthracene (DMBA)-induced breast cancer (Group III) animals were revived to the normal conditions in polysaccharide treated breast cancer (Group IV) animals as that of normal (Group I). The level of tumor markers CEA and CA 15.3, was found elevated in serum of DMBA-induced breast cancer groups (Group III) when compared to their levels in the normal groups (Group I) whereas polysaccharide treatment (Group IV) prevented this rise in the levels of tumor markers. The histological studies on the breast tissue samples of all the groups showed the appropriate features where the normal (Group I) animals were characterized with normal cells uniformly arranged without any change in orientation and morphology, DMBA-induced cancer (Group III) animals showed an improper orientation of cells arranged as glandular structures, as nest, or cords of various sizes or as solid sheets foci of necrosis in some areas with margins infiltrating, pushing, circumcised or mixed and the polysaccharide treated (Group IV) animals showed results resembling that of the normal (Group I) animals.

Conclusion: Thus, polysaccharide is proved as an effective chemo preventive agent against breast cancer.

Keywords: Chemoprevention, Blood cells, Cancer antigen, Tissue morphology

(C) 2019 The Authors. Published by Innovare Academic Sciences Pvt Ltd. This is an open-access article under the CC BY license (http://creativecommons.org/licenses/by/4.0/) DOI: http://dx.doi.org/10.22159/ijpps.2019v11i5.19756

\section{INTRODUCTION}

Cancer is one of the dreadful diseases taking away millions of life and its prevalence is expected to rise five-fold by 2025 [1]. According to the National Cancer Institute survey reports, the most prominent cancer occurring in males are pharyngeal and oral cancer (62.7\%), oesophagus cancer (8.4\%), lung cancer $(16.8 \%)$ and prostate cancer $(98.9 \%)$ and in females are cervical cancer $(67.9 \%)$ and breast cancer (89.2\%) [2]. There is no single treatment strategy for cancer, and the patients often receive a combination of therapies and palliative care such as surgery, chemotherapy, immunotherapy, hormone therapy and gene therapy, etc. The main drawback with these therapies is that they are accompanied with severe side effects. Hence generally it is necessary to explore effective agents to treat cancer with lesser side-effects. In ancient India, medicinal plants were used to prevent various critical diseases [3]. Plant or plant-based medicines are examined from the past in the system of ayurvedha and medicinal herbs mediated therapeutic approaches are of current interest for their potential biological effect that is free from drastic side-effects [4].

Tinospora cordifolia (T. cordifolia) belonging to Menispermaceae family has been extensively studied as a potential herb to treat various human illnesses. The stem of $T$. cordifolia was used as an important constituent in several ayurvedic preparations to cure general debility, dyspepsia, fever and urinary diseases, stomach problems, skin burns. The stem is bitter, stomachic, diuretic [5] disorders in bile secretion, constipation, vomiting, jaundice, anemia, etc. T. cordifolia rich in secondary metabolites produced certain curative properties such as antioxidant [6], anti-inflammatory [7], antibacterial [8], anti-hyperlipidemic [9], cholesterol-lowering [10], hepatic protective effects [11] and diuretic activities [12], antipyretic [13], radioprotective [14] etc. Polysaccharide identified as one of the active principles present in the methanolic extract of $T$. cordifolia stem bark has been previously reported to possess antidiabetic property on STZ-induced diabetic Wistar rats showing an increase in insulin secretion and glucose utilization in polysaccharide treated animal models [15]. The anti-diabetic potential of a phytocompound is the correlation with its anticancer activity and hence polysaccharide has been explored in the present study for identifying its efficacy in treating cancer.

\section{MATERIALS AND METHODS}

\section{Chemicals and reagents}

All chemicals and reagents used were of extra pure and culture Grade, procured from suppliers such as Sigma Chemical Pvt Ltd, USA; Himedia Chemicals, Mumbai. All solvents were obtained from Fischer Scientific Ltd, India.

\section{Isolation of polysaccharide}

Polysaccharide was isolated from the methanolic extract of $T$. cordifolia stem bark, by the protocol of Rajalakshmi et al [16] .

\section{In vivo studies}

\section{Animals}

Female albino Wistar rats aged between 50 and $55 \mathrm{~d}$ was procured from Tamil Nadu Vertinary Sciences, Madhavaram. The animals were maintained under controlled environmental conditions on an alternative 12-h dark/light cycle. Commercial pelleted feed supplied by Sai enterprises Ltd., Chennai and water ad libitum were given to animals. This research work on albino Wistar rats was sanctioned and approved by the Institutional Animal Ethical Committee (IAEC No. 07/2013). 


\section{Experimental setup}

The animals were divided into five groups with six animals each. Group I animals served as normal control, Group II was normal animals supplemented with polysaccharide $(20 \mathrm{mg} / \mathrm{kg}$ body weight (bwt), Group III was animals treated with $20 \mathrm{mg}$ of DMBA in $1 \mathrm{ml}$ corn oil to induce breast cancer. Group IV was animals treated with DMBA and simultaneously supplemented with polysaccharide $(20 \mathrm{mg} / \mathrm{kg}$ body weight). Group V was animals treated with DMBA and simultaneously supplemented with Paclitaxel $(1 \mathrm{mg} / \mathrm{kg}$ body weight). The overall induction and treatment period was $3 \mathrm{mo}^{*}$ for all groups. After the experimental period, the animals were sacrificed by decapitation, breast and liver tissues were dissected out and tissue homogenates were prepared in $0.1 \mathrm{M}$ Tris- $\mathrm{HCl}$ buffer $\mathrm{pH} 7.4$ which were stored at $80^{\circ} \mathrm{C}$, until their use for further analysis.

\section{Hematological parameters}

The hematological parameters-Red blood cell (RBC), White blood cell (WBC) and platelet counts were measured using an automated cell counter.

\section{Estimation of tumor markers}

The tumor markers Carcino Embryonic Antigen (CEA) and Cancer Antigen 15.3 (CA 15.3) were estimated by the method of Chemi Luminescence Immune Assay [17].

\section{Histological studies}

Breast tissues from the untreated and the experimental groups were blotted free of mucus, washed in physiological saline and fixed in
Bouin-Hollande fixative for $74 \mathrm{~h}$. After fixation, the tissues were washed in $70 \%$ alcohol for two or three days to remove the excess picric acid and then dehydrated in graded series of alcohol. The tissues were cleared using xylene. The cleared tissues were infiltrated with molten paraffin at $58-60{ }^{\circ} \mathrm{C}$ through three changes (20-30 $\mathrm{min})$ and finally embedded in paraffin. Sections of the tissues were obtained using rotary microtome and stained in Ehrlich's hematoxylin with eosin as the counterstain. The slides were mounted using DPX mountant [18].

\section{Statistical analysis}

The data were analyzed using the SPSS Windows Students version software. For all the measurement, one-way ANOVA followed by Duncan's Multiple Range Test [19] was used to assess the statistical significance of the difference between control and treated groups. A statistically significant difference was considered at the level of $\mathrm{p}<0.05$.

\section{RESULTS}

\section{Effect of polysaccharide on RBC, WBC and platelet counts}

Analysis of the anticancer potential of polysaccharide on RBC, WBC and platelet counts in DMBA-induced breast cancer rats was done in the present study. When compared to the normal (Group I) animals the levels of RBC, WBC and platelets were found to be in a decreased condition in DMBA-induced breast cancer (Group III) animals. The polysaccharide treatment (Group IV) revived the levels RBC, WBC and platelets as in that of normal animals (fig. 1,2 and 3). Thus, polysaccharide has a potency to prevent the depletion of blood cells in cancer conditions.

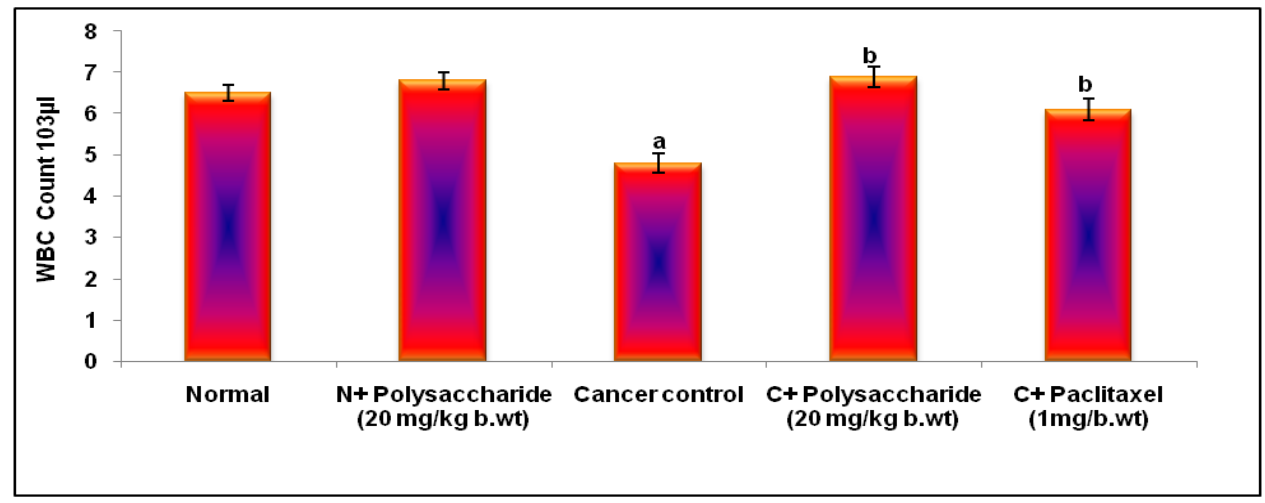

Fig. 1: Effect of polysaccharide on WBC and platelets in female albino wistar rats. Each bar represents mean \pm SEM of 6 animals, significance at $p<0.05$, a-compared with normal, b-compared with DMBA-induced

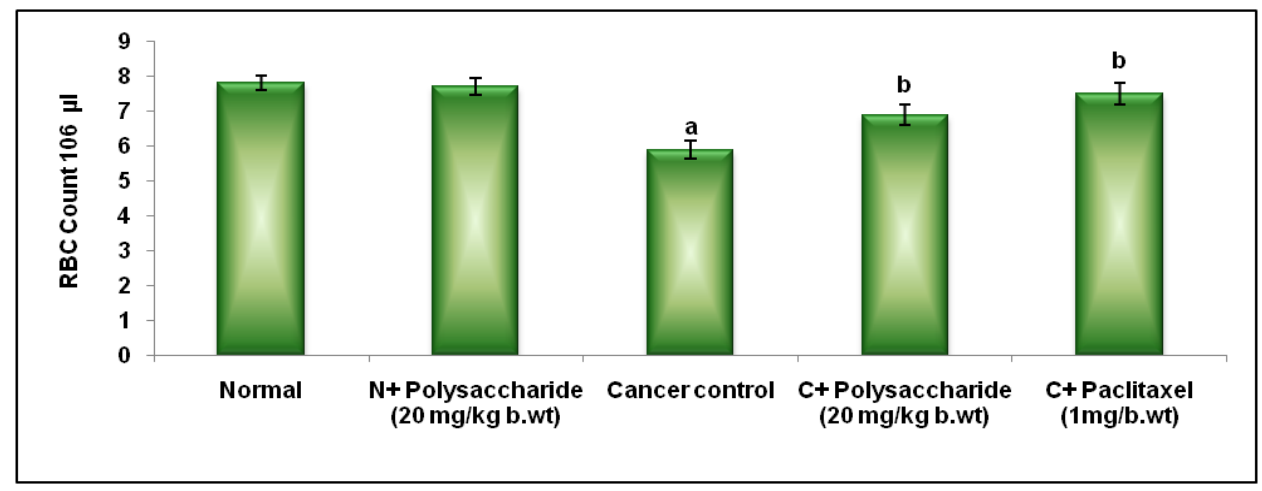

Fig. 2: Effect of polysaccharide on RBC and platelets in female albino wistar rats. Each bar represents mean \pm SEM of 6 animals, significance at $p<0.05$, a-compared with normal, b-compared with DMBA-induced

\section{Effect of polysaccharide on CEA}

The level of tumor marker CEA, was estimated in the serum of normal, cancer and treated animal groups and the results obtained showed an elevated levels of CEA in the DMBA-induced breast cancer groups (Group III) when compared to their levels in the normal groups (Group I) whereas polysaccharide treatment (Group IV) prevented the elevated of CEA, thus the efficacy of the polysaccharide in preventing tumor development is evident (fig. 4). 


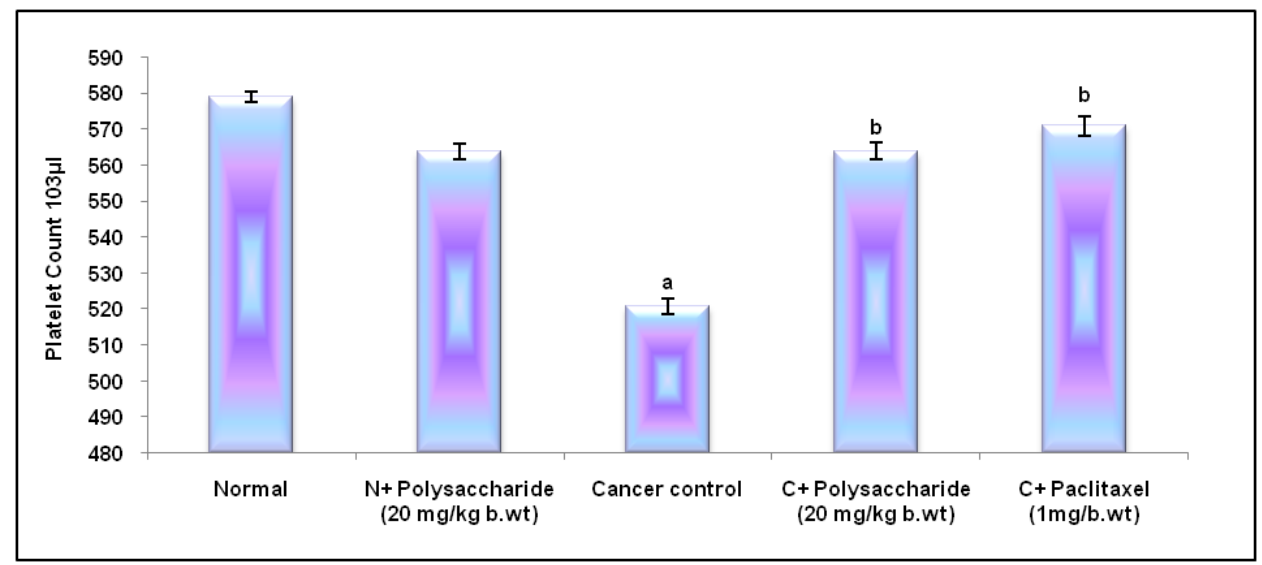

Fig. 3: Effect of polysaccharide on platelets in female albino wistar rats. Each bar represents mean \pm SEM of 6 animals, significance at $p<0.05$, a-compared with normal, b-compared with DMBA-induced

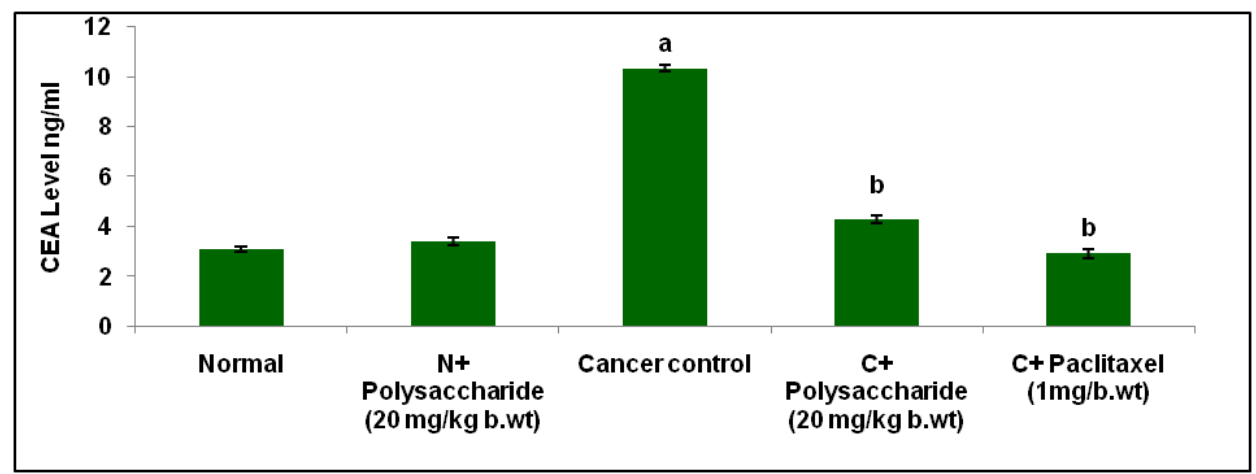

Fig. 4: Effect of polysaccharide on CEA in female albino wistar rats. Each bar represents mean \pm SEM of 6 animals, significance at $p<0.05$, acompared with normal, b-compared with DMBA-induced

\section{Effect of polysaccharide on CA 15.3}

The level of breast cancer-specific tumor marker CA 15.3 determined in the normal, cancer-induced and compound treated groups showed that the cancer control groups (Group III) had increased the levels of CA 15.3, whereas an only low level of the antigen was found in the normal control animals (Group I) and this normal level was also maintained in the polysaccharide treated animals (Group IV) (fig. 5). While treating the DMBA-induced rats with the polysaccharide, a normal level of the antigen was observed indicating the effect of the compounds in preventing the tumor development.

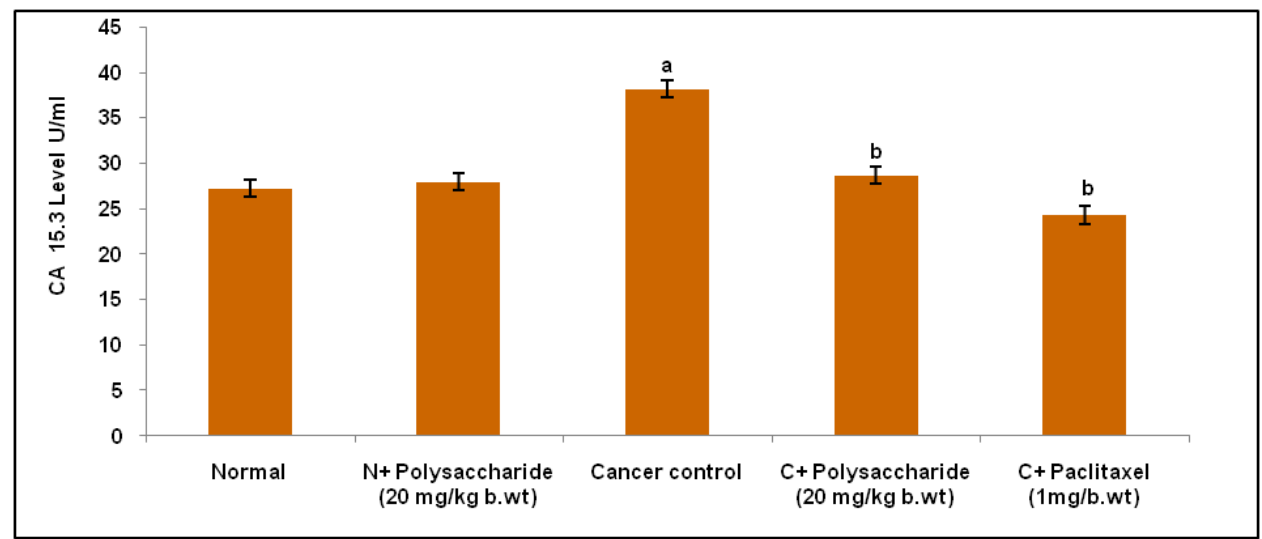

Fig. 5: Effect of polysaccharide on CA 15.3 in Female albino wistar rats, each bar represents mean \pm SEM of 6 animals, significance at p<0.05, a-compared with normal, b-compared with DMBA-induced

\section{Effect of polysaccharide on breast tissue}

The breast tissues of all the groups were subjected to histopathological analysis (fig. 6). The Group I breast tissue sections were characterized with normal cells uniformly arranged without any change in orientation and morphology. The tissue sections of DMBA-induced cancer animal (Group III) showed an improper orientation of cells. The tumor cells we rearranged as glandular structures, as nest, or cords of 
various sizes or as solid sheets foci of necrosis in some areas with margins infiltrating, pushing, circumcised or mixed. Observations done on the breast tissues taken from the polysaccharide treated animals
(Group IV) showed results resembling that of the normal (Group I) animals. Thus, the chemo preventive ability of polysaccharide was substantiated on the DMBA-induced breast cancer rat models.

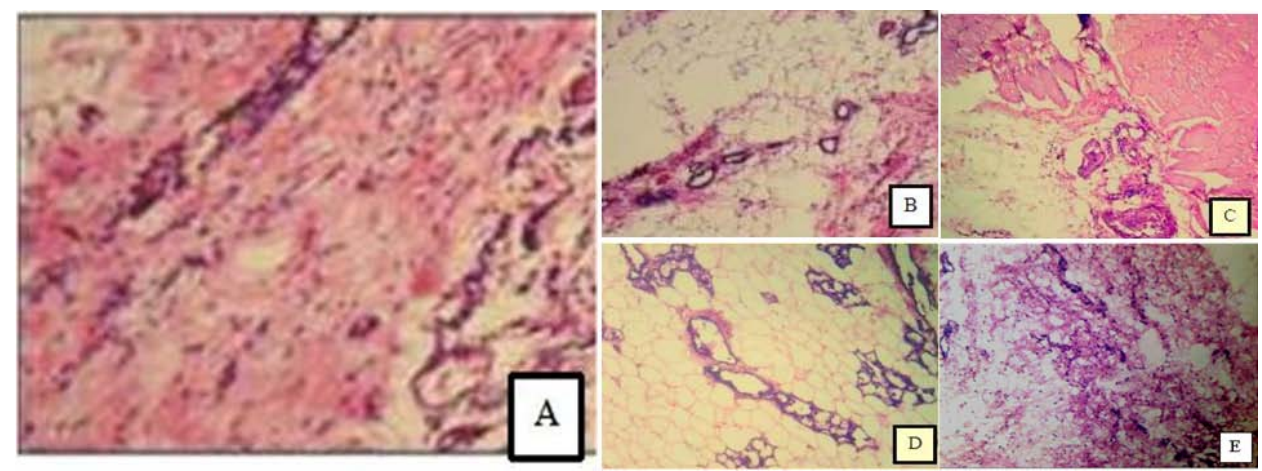

Fig. 6: Photomicrographs of histopathological changes in the mammary tissues of control and experimental animals on polysaccharide treatment, hematoxylin and eosin stained sections under light microscopy (x200), A-Normal control animals (Group I), B-Normal animals supplemented with polysaccharide $(20 \mathrm{mg} / \mathrm{kg}$ body weight) (Group II), C-DMBA-induced breast cancer animals (Group III), D-Animals treated with DMBA and simultaneously supplemented with polysaccharide $(20 \mathrm{mg} / \mathrm{kg}$ body weight) (Group IV), E-Animals treated with DMBA and simultaneously supplemented with paclitaxel ( $1 \mathrm{mg} / \mathrm{kg}$ body weight) (Group V)

\section{DISCUSSION}

The present scenario is of great interest in the search for novel drugs, especially of plant origin to develop effective drug molecules with potential activities. There are several studies reported suggesting the potential roles of plant-based molecules as anticancer agents under various systems of analysis including animal models [20]. In general, the number of circulating erythrocytes under various physiological conditions is maintained by the process of erythropoiesis and various pathological conditions including malignancy is associated with any alteration in this process [21].

Generally, the hormone erythropoietin (Epo) is involved in the maintenance of normal RBC levels, under cancer induced hypoxia conditions Epo production is depreciated thus favoring low levels of RBCs [22]. Similarly, the RBC and WBC counts were found to get decreased by chemotherapeutic agents. Also, cancer in bone marrow which serves as a reservoir for the production of blood cells slows down its functioning capability. The tumor cells induced platelet aggregation is one of the phenomenal states in cancer development where tumor cell are encapsulated by the platelets in order to save them from the action of tumor necrosis factor and to succeed in metastasis. This resulted in the reduction in the count of freely circulating platelets. The polysaccharide treatment retrieved the equilibrium conditions of blood cell counts controlling the normal gene expression.

CEA and CA 15.3 are the most widely used breast cancer markers [23]. These antigens are found to be at different levels of breast carcinoma based on the various stages of cancer [24]. CEA is a glycoprotein, generally expressed in fetal condition and its expression stops before birth. In normal adults, only a minute level of the antigen is observed, but several reports suggest that the level of CEA to be significantly elevated from normal levels in breast cancer conditions [25-27]. CA 15.3 is also a serum marker for breast cancer that generally helps in cell adhesion and their elevation to high levels is observed in cancer condition [28, 29]. Polysaccharide supplementation in DMBA-induced breast cancer rats controlled the expression levels as that in normal cells.

\section{CONCLUSION}

The polysaccharide isolated from the methanolic extract of $T$. cordifolia stem bark had activity against breast cancer. Hence, with further studies, the novel polysaccharide can be used as a potential anticancer phyto-compound in therapeutic drug development.

\section{ACKNOWLEDGMENT}

The work was supported by the grant from University Grants Commission (UGC) (F. No. MRP-5094/14 (SERO/UGC) and DBT-BIF,
Ministry of Science andamp; Technology, Govt. of India New Delhi for infrastructure facility.

\section{AUTHORS CONTRIBUTIONS}

Research guidance-Manikkam Rajalakshmi, Laboratory and experimental work, writing the article-Antony Ludas, Manuscript writing-SabapathyIndu, Laboratory work-Sekar Hinduja, Laboratory work-Anthonisamy Kumari Nirmala.

\section{CONFLICT OF INTERESTS}

Declared none

\section{REFERENCES}

1. Vanishree Shriraam, Shiraam Mahadevan, Anitharani, Selvavinayagam M, Sathiyasekaran BWC. National health programs in the field of endocrinology and metabolism-Miles to go. Indian J Endocrinol Metab 2014;18:7-12.

2. Yong-chuan Wang, Li-juan Wei, Jun-tian Liu, Shi-xia Li, Qingsheng Wang. Comparison of cancer incidence between china and the USA. Cancer Biol Med 2012;9:128-32.

3. Parekh J, Chanda S. Phytochemicals screening of some plants from the western region of India. Plant Arch 2008;8:657-62.

4. Premalatha B, Rajgopal G. Cancer-an ayurvedic perspective. Pharmacol Res 2005;51:19-30.

5. Nayampalli SS, Ainapure SS, Samant BD, Kudtarkar RG, Desai NK, Gupta KC. A comparative study of diuretic effects of Tinospora cordifolia and hydrochlorothiazide in rats and a preliminary phase I study in human. J Postgrad Med 1988;34:233-6.

6. Tamboli, Saleem B, Sumit P Sontakke, Rahul B Parsode. Study of hypoglycemic activity of Tinospora cordifolia in alloxaninduced diabetic rabbits. Int J Basic Clin Pharmacol 2013;559-61.

7. Raghunathan K, Sharma PV. Effect of $T$. cordifolia miers (Guduchi) on alloxan induced hyperglycemia.J Res Indian Med 1969;3:203-9.

8. Jeyachandran R, Francis Xavier T, Anand SP. Antibacterial activity of stem extracts of Tinospora cordifolia (Willd) hook. fand thomson. Anc Sci Life 2003;23:40-3.

9. Thahera, Parveen D, Shaik Nyamathulla. Antihyperlipidemic activity of the methanolic extract from the stems of Tinospora cordifolia on sprague dawley rats. Pelagia Res Library Der Pharm Sinica 2011;2:104-9.

10. Stanely Mainzen Prince P, Menon VP. Hypoglycaemic and hypolipidaemic action of alcohol extract of Tinospora cordifolia 
roots in chemical induced diabetes in rats. Phytother Res 2003; 17:410-3.

11. Sharma V, Pandey D. Protective role of Tinospora cordifolia against lead-induced hepatotoxicity. Toxicol Int 2010;17:12-7.

12. Nadkarni KM. Indian material medica. In: Nadkarni KM. editor. Bombay: Popular Book Depot; 1954. p. 1228.

13. Duraisankar M, Ravichandran V. Antipyretic potential of polyherbal ayurvedic products. Asian J Pharm Clin Res 2012;5:146-50.

14. Priyanka Sharma, Pradeep K Goyal. Modulation of biochemical and antioxidant enzymes in blood by Tinospora cordifolia against gamma radiation-mediated damage in mice. Asian J Pharm Clin Res 2015;8:106-12.

15. Manikkam Rajalakshmi, Roy Anita. $\beta$-cell regenerative efficacy of a polysaccharide isolated from a methanolic extract of Tinospora cordifolia stem on streptozotocin-induced diabetic wistar rats. Chem Biol Interact 2016;243:45-53.

16. Rajalakshmi M, Eliza J, Cecilia Edel Priya, Nirmala A, Daisy P. Anti-diabetic properties of Tinospora cordifolia stem extracts on streptozotocin-induced diabetic rats. Afr J Pharm Pharmacol 2009;3:171-80.

17. Coombes RC. Tumor-markers-their role in clinical cancer management. J Clin Chem Clin Biochem 1981;19:216.

18. Humason GL. Animal tissue techniques. WH Freeman and Company, San Francisco. 4th edition; 1979.

19. Duncan BD. Multiple range tests for correlated and heteroscedastic means. Biometrics 1957;13:164-76.

20. Sun Y. Structure and biological activities of the polysaccharides from the leaves, roots and fruits of Panax ginseng C. A. Meyer: an overview. Carbohydr Polym 2011;85:490-9.
21. Birgergard G, Aapro MS, Bokemeyer C, Dicato M, Drings P, Hornedo J. Cancer-related anemia: pathogenesis, prevalence and treatment. Ann Oncol 2005;68:3-11.

22. Bhuavaneswari S, Murugesan S. Antitumor activity of Chondrococcus hornemanni and Spyridia fusiformis on dalton's lymphoma ascites in mice. Bangladesh $J$ Pharmacol 2012;7:173-7.

23. Duffy MJ. Serum tumor markers in breast cancer: are they of clinical value? Clin Chem 2006;52:345-51.

24. Waalkes TP, Enterline JP, Sharper JH, Abeloff MD, Ettinger DS. Biological markers for breast carcinoma. Cancer 1984;53:64-51.

25. Beard DB, Haskell CM. Carcinoembryonic antigen in breast cancer, clinical review. Am J Med 1986;80:40-5.

26. Loprinzi CL, Tormey DC, Rasmussen P, Falkson G, Davis TE, Falkson $\mathrm{HC}$, et al. Prospective evaluation of carcinoembryonic antigen levels and alternating chemotherapeutic regimens in metastatic breast cancer. J Clin Oncol 1986; 4:46-56.

27. Colomer R, Ruibal A, Salvader L. Circulating tumor marker levels in advanced breast carcinoma correlate with the extent of metastatic disease. Cancer 1989;64:1.

28. Duffy MJ, Shering S, Sherry F, McDermott E, O'Higgins N. CA 153:a prognosticmarker in breast cancer. Int J Biol Markers 2000;15:330-3.

29. Lakshmi A, Subramanian S. Chemotherapeutic effect of tangeretin, a polyethoxylated flavones studied in 7, 12dimethylbenz (a) anthracene induced mammary carcinoma in experimental rats. Biochimie 2014;99:96-109. 